\title{
Gout gone awry: the importance of proper diagnosis
}

\author{
Sophia Tessema ${ }^{1}$, Abdullahi Mahgoub ${ }^{2}$, and Rasha Nakhleh ${ }^{3}$ \\ ${ }^{1}$ Michigan State University \\ ${ }^{2}$ Hurley Medical Center \\ ${ }^{3}$ Oregon Health \& Science University
}

July 28,2020

\begin{abstract}
Gout is the best known type of arthritis with a prevalence of $1-3 \%$ in the western world $[1,2]$. Although well understood there is growing evidence of the misdiagnosis of gout from other forms of arthritis. These errors lead to delay in accurate diagnosis and in appropriate care [2]
\end{abstract}

\section{Gout gone awry: the importance of proper diagnosis}

1. Sophia Tessema, MD, MPH

Neuro-Ophthalmology Fellow, Michigan State University, Hurley Medical Center. Mailing Address: 965 Fee Rd. A110, East Lansing, MI 48824, USA. Email: tessemas@msu.edu

2. Abdullahi E. Mahgoub, MD

Geriatric Fellow, Geriatric Medicine Department, Hurley Medical Center. Mailing Address: 1 Hurley Plaza, Flint, MI 48503, USA. Email: abdullahimahgoub@gmail.com

3. Rasha Nakhleh, MD, AGSF

Assistant Professor of Medicine Division of General Internal Medicine \& Geriatrics Oregon Health \& Science University Mailing Address: 3181 SW Sam Jackson Park Rd L475, Portland, OR 97239, USA. Email: nakhlehr@ohsu.eduCorrespondence:

Rasha Nakhleh, MD, AGSF

Assistant Professor of Medicine Division of General Internal Medicine \& Geriatrics Oregon Health \& Science University Mailing Address: 3181 SW Sam Jackson Park Rd L475, Portland, OR 97239, USA. Email: nakhlehr@ohsu.edu

\section{Key Clinical Message:}

Gout is the best known type of arthritis with a prevalence of 1-3\% in the western world.[1,2] Although well understood there is growing evidence of the misdiagnosis of gout from other forms of arthritis. These errors lead to delay in accurate diagnosis and in appropriate care for patients with gout.[2]

\section{Case Description:}

A 76 year old Caucasian male presented to the clinic with concerns regarding gait abnormalities for the last 4 months, pain in the arch of his feet, and numbness and discomfort in multiple joints. The patient 
had noted pain and stiffness in his wrists 17 years ago. He was subsequently evaluated and diagnosed with osteoarthritis. Since that time, he managed his pain with meloxicam. Approximately 12 years later, he noticed the sudden onset of nodules in his joints. The patient had no prior investigation of possible gout and believed his symptoms were due to osteoarthritis. Physical examination revealed bilateral large firm tophi on his hands, elbows, knees and feet with ulceration and chalky white discharge noted on his index fingers. Radiologic x-ray films noted diffuse soft tissue tophi, destructive changes involving the distal half of the intermediate phalanx of the 5th finger in the proximal half of the distal phalanx and erosive changes of the ulnar styloid. Laboratory workup revealed a slightly increased uric acid level of $8.6 \mathrm{mg} / \mathrm{dL}$. Radiologic x-ray films noted diffuse soft tissue tophi. Patient was started on Allopurinol and later switched to Pegloticase infusion therapy. Significant improvement of joint stiffness and tophus size was noticed 6 months after continuation of therapy.

\section{Learning Points:}

- Gout may be misdiagnosed as other forms of joint disease, particularly osteoarthritic changes. It is important to recognize the distinction between these diseases and to do so early to prevent irreversible joint destruction.

- The role of medication such as Pegloticase can prove beneficial in improving patient outcomes without the need for surgery in significantly progressed cases of gout, such as this patient's gout.

\section{Informed Consent}

Informed consent has been obtained for the publication of this clinical image.

\section{Authorship}

All the authors made substantial contributions to the preparation of this manuscript and approved the final version for submission.

\section{Conflict of Interest}

The authors have declared that no conflict of interest exists.

\section{References}

1. Chowalloor, P. V., Siew, T. K., \& Keen, H. I. (2014). Imaging in gout: A review of the recent developments. Therapeutic Advances in Musculoskeletal Disease , 6 (4), 131-143. https://doi.org/10.1177/1759720X14542960

2. Ragab, G., Elshahaly, M., \& Bardin, T. (2017). Gout: An old disease in new perspective - A review. Journal of Advanced Research ,8 (5), 495-511. https://doi.org/10.1016/j.jare.2017.04.008 

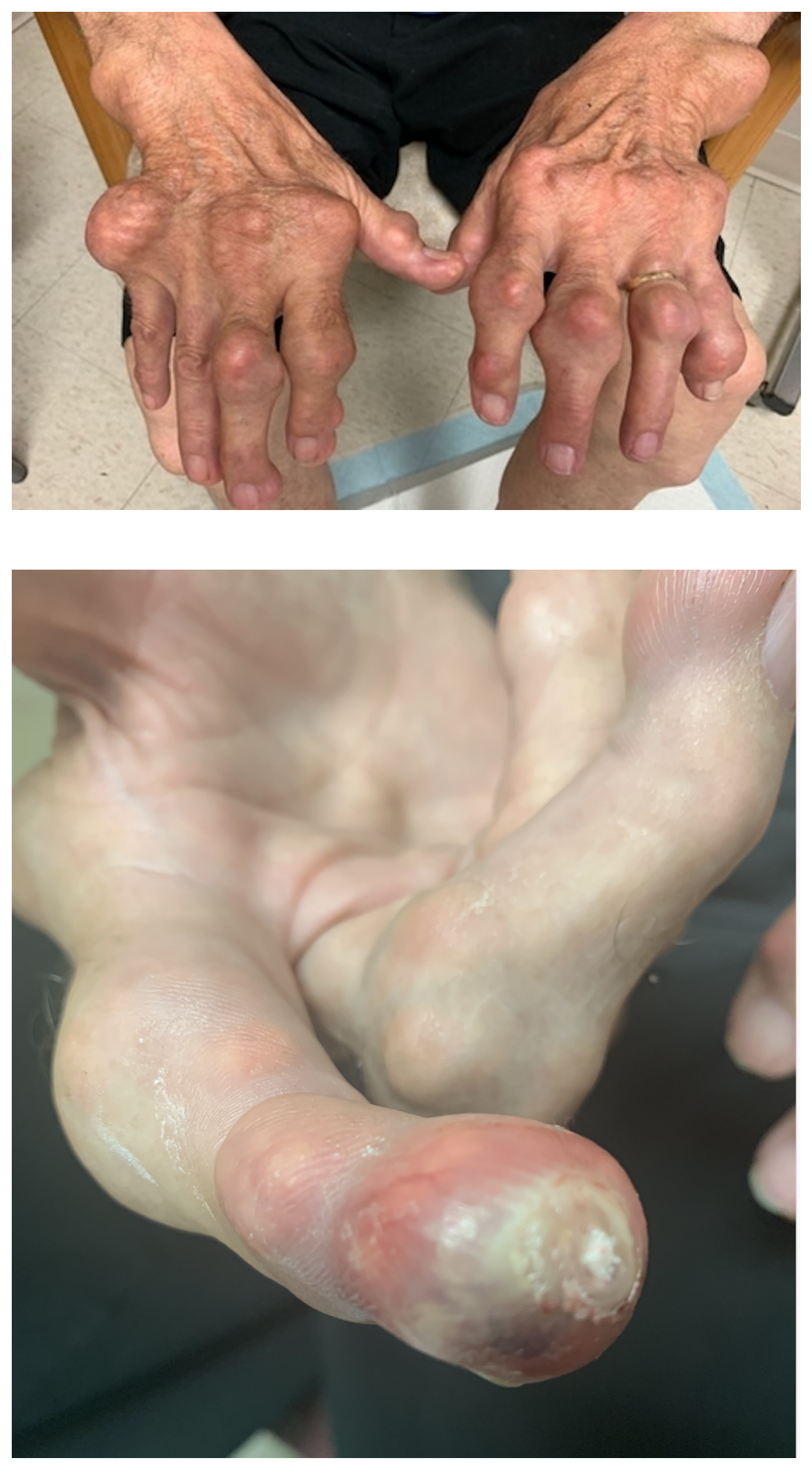


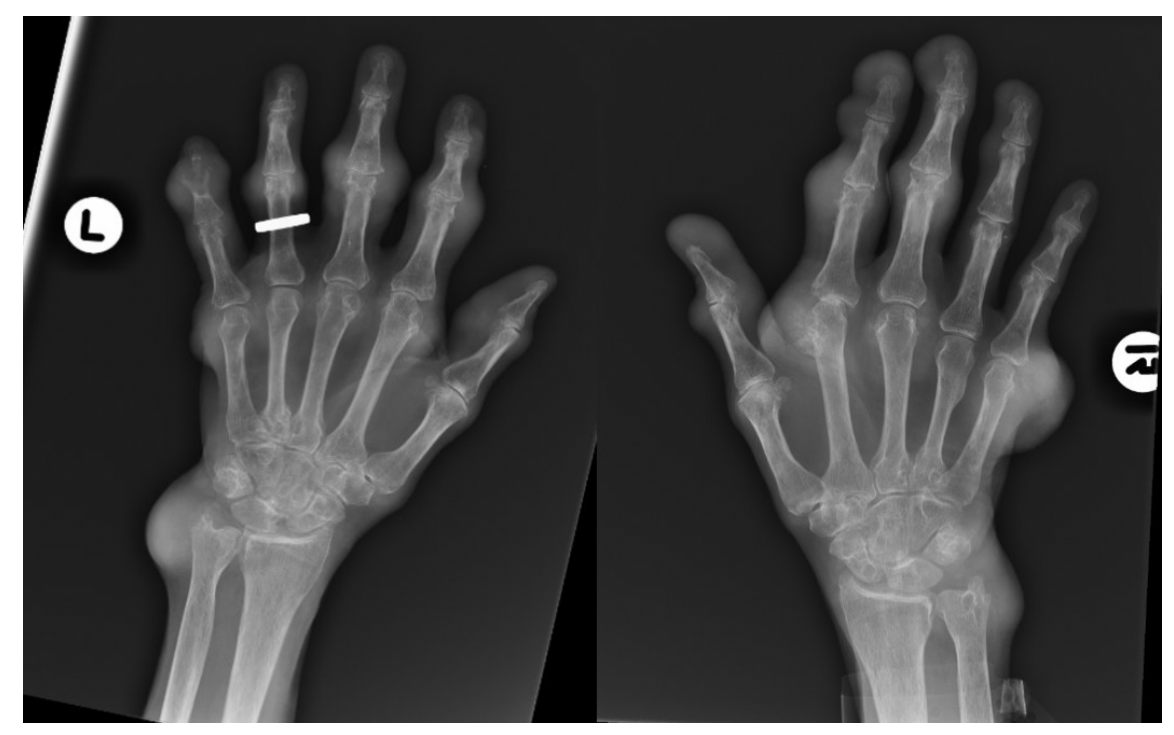




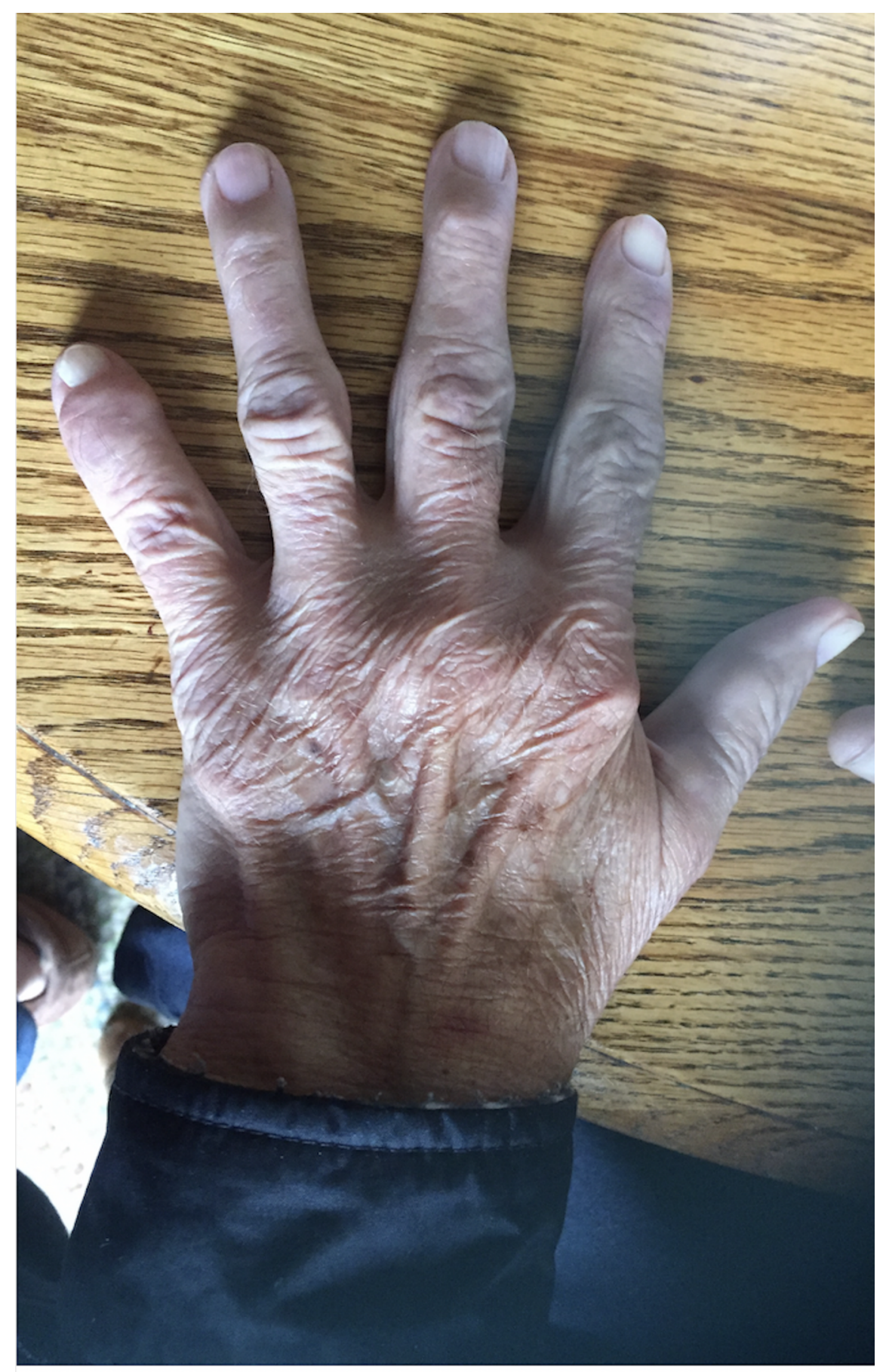




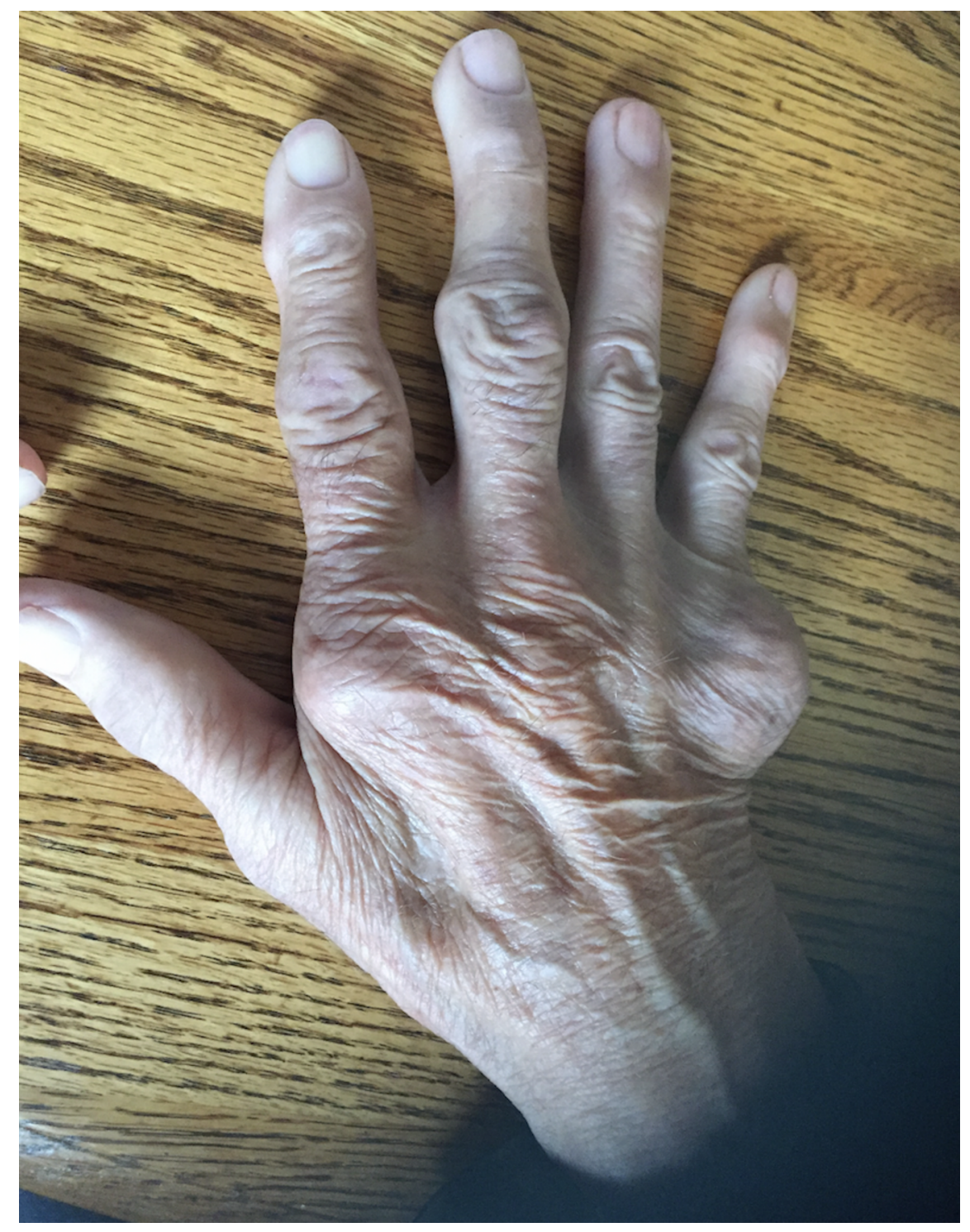

